\title{
O Portfólio na Avaliação da Aprendizagem no Ensino Presencial e a Distância: a alternativa hipertextual
}

\author{
LINA CARDOSO NUNES \\ Professora da Universidade Estácio de Sá \\ linanunes@brturbo.com.br
}

\begin{abstract}
Resumo
Este artigo tem por objetivo relatar a experiência proposta em uma disciplina de mestrado em educação, vinculada à linha de pesquisa Tecnologias da Informação e Comunicação, de caráter presencial, por um professor-pesquisador, preocupado com uma prática pedagógica que viabilize a articulação dos processos de ensinar, aprender e avaliar, para a construção de um hipertexto. Foi sugerida, aos alunos, a elaboração do portfólio digital, que seria entregue ao final do semestre, na perspectiva de implementar uma modalidade alternativa de avaliar que pudesse ser aplicada em disciplinas presenciais e a distância. Coerente com os conteúdos da disciplina e fundamentado na possibilidade da produção de um hipertexto, o portfólio digital, constituiu uma alternativa valiosa para o processo de aprender-ensinaravaliar.
\end{abstract}

Palavras-chave: portfólio, avaliação, aprendizagem.

\section{Resumen}

Este artículo tiene como objetivo relatar la experiencia propuesta en una asignatura de un master en educación, vinculada a la línea de investigación en Tecnologías de Información y Comunicación (con carácter presencial). Fue realizada por un profesor investigador preocupado por una práctica pedagógica que viabilice la articulación de los procesos de enseñar, aprender y evaluar, para la construcción de un hipertexto. Se sugirió a los alumnos la elaboración de un portfolio digital para entregar al final del semestre, con el objetivo de implementar una forma alternativa de evaluación, que pudiese ser empleada en asignaturas presenciales y a distancia. Coherente con los contenidos de la materia y fundamentado en la posibilidad de producción de un hipertexto, el portfolio digital constituyó una valiosa alternativa para el proceso de aprender - enseñar - evaluar.

Palabras clave: portfolio, evaluación, aprendizaje.

\begin{abstract}
The purpose of this article is to give an account of an experiment proposed in a Master's course in Education as part of a research field in Information Technologies and Communications in which the researcher intended to take into account a pedagogical practice that would allow for the integration of teaching, learning and evaluation processes in the construction of a hypertext. It was suggested that students work on a digital portfolio to be handed in at the end of the term, as an alternative evaluation mode to be used in live and distance education courses. Coherent with the course content and based on the possibility of producing a hypertext, the digital portfolio proved to be a valuable alternative in the teaching, learning and evaluation processes.
\end{abstract}

Key words: portfolio, evaluation, learning. 


\section{APRESENTANDO A PROPOSTA}

São inúmeros os desafios que se apresentam no mundo contemporâneo em diferentes espaços educacionais, tanto no ensino presencial quanto no ensino a distância, diante da revolução trazida pelos dispositivos midiáticos, emergindo questões relacionadas às redes digitais e às transformações das modalidades de aprendizagem (Assmann, 2005) que apontam para a temática do "letramento digital" (Coscarelli, 2005, p. 31).

Destaca-se, nessa perspectiva, um novo conceito de alfabetizar, que não se limita a ensinar a ler e a escrever, mas vai além, configurando o processo de letramento - compreendido por Soares (1998, p. 47) como um estado ou condição de quem não apenas aprende a ler e escrever, mas cultiva as práticas sociais que usam a escrita. Ao citarmos o letramento digital, retomamos o pensamento de Soares (2002, p. 151), que o define como certo estado ou condição que adquirem os que se apropriam de nova tecnologia digital e exercem práticas de leitura e escrita na tela, diferente do estado ou condição do letramento - dos que exercem práticas de leitura e escrita no papel (apud Goulart, 2005).

Importa, nesse sentido, a reflexão sobre as alternativas de aprenderensinar-avaliar nesse novo espaço, constituído de oportunidades de aprofundar saberes e práticas, no âmbito da sociedade da informação, com possibilidades pedagógicas inusitadas, se comparadas às propiciadas há duas décadas, no final de século XX.

Assim, este artigo tem por objetivo relatar uma experiência proposta na disciplina "Avaliação educacional e mediação tecnológica", de caráter presencial, por um professor-pesquisador, preocupado com uma prática pedagógica que viabilize a articulação dos processos de ensinar, aprender e avaliar. Foi sugerido aos alunos, inicialmente, a aplicação do portfólio digital, na perspectiva de implementar uma modalidade alternativa de avaliar que pode ser aplicada em disciplinas presenciais e a distância.

\section{O PORTFÓLIO: UMA ALTERNATIVA HIPERTEXTUAL}

O portfólio, inicialmente utilizado na arte, constitui a reunião das produções em um caderno/bloco/pasta, que apresenta tudo o que o autor elabora e constrói em sua trajetória artística, como evidência de seu progresso ou desenvolvimento. A transposição do portfólio para o processo de ensinar aprender e avaliar se configura numa experiência significativa para a prática pedagógica, visto que mostra passo-a-passo como 
professores e alunos encaminham a construção progressiva dos conhecimentos nos temas abordados na disciplina.

No caso deste relato, o portfólio foi elaborado com todas as produções individuais e coletivas dos alunos, emergentes das atividades desenvolvidas, com base em textos propostos pelo professor, outros acessados na Internet pelos alunos, ou coletados em livros e revistas científicas com temas relacionados à disciplina: "Avaliação educacional e mediação tecnológica". Assim, foi-se constituindo, no decorrer do curso, um hipertexto criativo, originário da rede de saberes dos participantes, que se juntou aos dos autores lidos e comentados. De acordo com Assmann (2005, p.21) no interior de cada hipertexto deparamo-nos com um conjunto de nós interligados por conexões, nos quais os pontos de entrada podem ser palavras, imagens, icones e transações de contatos multidimensionais (links).

Para Coscarelli (2003, p.21), os hipertextos, por sua vez, contam ou podem contar com a presença de imagens, outras marcas como os hiperlinks, as barras de rolamento, diferentes formas de mostrar que um botão está ou não ativado, sons, gráficos, animações, vídeos, entre outros.

Cabe esclarecer, conforme explica Coscarelli (2003, p.67), que:

[...] uma das características essenciais a qualquer gênero textual é o caráter sóciocomunicativo e decorrentes disso, os aspectos pragmáticos envolvidos no ato de comunicação. Todo texto para ser recebido (não necessariamente compreendido) por alguém; é produzido por alguma intenção comunicativa que o leitor tem o trabalho de recuperar.

Nesse caso, o portfólio, numa dimensão hipertextual, aponta também para essas características, em especial no que tange à sociocomunicação, visto que é gerado por muitas pessoas, numa dimensão colaborativa, com a contribuição das tecnologias digitais.

De acordo com Souza (2003, p. 95) há um aprendizado que ocorre espontaneamente nas comunicações que surgem em torno de algumas tecnologias eletrônicas de interação, as chamadas comunidades virtuais. Nesses ambientes, configura-se a abertura de espaços para a hipertextualidade, definida por Assmann (2005, p. 21) como um vasto conjunto de interfaces comunicativas, disponibilizadas nas redes telemáticas.

Aqui, é oportuno assinalar as relações do hipertexto com o letramento, uma vez que na elaboração do hipertexto é importante o letramento, como prática de saber ler e escrever (Soares, 1998), dominando o código escrito e do letramento digital, por meio do qual há a apropriação da leitura na tela do computador como condição de selecionar textos significativos nos contextos em que se está construindo o hipertexto. Assim, se evidenciam as relações entre o letramento digital e o hipertexto, pois a 
construção deste implica o domínio da leitura e da escrita de textos na tela do computador.

O hipertexto, para Levy (1999, p.56), é constituído por nós (os elementos de informação, parágrafos, páginas, imagens, seqüências musicais, etc.) links entre esses nós, referências, notas, ponteiros, botões, indicando a passagem de um nó a outro. Configura-se, especialmente neste artigo, a possibilidade de construir um texto, de forma não-linear, com a leitura de diferentes materiais coletados no decorrer das aulas: em livros, Internet, jornais impressos e/ou online, diálogos por e-mail, listas de discussão, grupos presenciais, relacionando todas as informações, com coerência e coesão, em torno da temática da disciplina.

Abre-se, nesse âmbito, espaço para o conceito de inteligência coletiva, que segundo Levy (1998) propicia a cooperação cognitiva entre os que compartilham as possibilidades do uso do computador e da Internet.

\section{A APLICAÇÃO DO PORTFÓLIO: MODALIDADE DE AVALIAÇÃO ALTERNATIVA}

A proposta de aplicação do portfólio da disciplina presencial "Avaliação educacional e mediação tecnológica" se efetiva na perspectiva anunciada por Levy (1998), abrindo espaços para a cooperação online, conferindo status à dimensão cognitiva dessa modalidade de avaliar. Além de sua aplicabilidade ser adequada ao ensino presencial, configura-se como um procedimento avaliativo coerente com os referenciais teóricos assumidos na disciplina em foco (Soares, 1998; Assmann, 2005; Levy, 1998; Coscarelli, 2005, entre outros).

$\mathrm{O}$ alunos foram orientados para que reunissem todos os materiais para a elaboração do portfólio digital, que seria entregue ao final do período, em $c d$-rom, no qual estariam todas as atividades realizadas com os textos analisados em sala de aula, os acessados na Internet, ou ainda decorrentes de leituras relacionadas aos temas estudados, constituindo um hipertexto, em que fiquem evidenciadas as relações entre as idéias principais e as palavras-chave relativas aos objetivos da disciplina.

A concepção orientadora dessa atividade é ligada à aprendizagem colaborativa propiciada, especialmente pelas redes telemáticas. Souza (2003, p.100) assiná-la que para se conseguir a máxima efetividade no processo de aprendizagem são necessários o engajamento e a participação ativa. Essas condições são compreendidas como significativas, tanto no ambiente presencial quanto no online. As atividades propostas no decorrer da disciplina configuravam a importância da atividade colaborativa, 
representada especialmente pela criação de um grupo na Internet, na perspectiva de articular os conteúdos da disciplina. O grupo foi denominado Avaliação-Mediação, do qual faziam parte a professora e todos os alunos e alunas.

Alguns sujeitos demoraram mais que outros para se filiarem ao grupo. A responsável pela sua formação foi uma das alunas (BR), que durante o período esteve sempre envolvida ativamente nas ações propostas pela professora. Neste artigo, os componentes estão representados por duas letras maiúsculas, como se segue: $\mathrm{AV}, \mathrm{AN}, \mathrm{CF}, \mathrm{BR}, \mathrm{GC}, \mathrm{LD}, \mathrm{LM}, \mathrm{MI}, \mathrm{MB}$, $\mathrm{MC}, \mathrm{NK}, \mathrm{PB}, \mathrm{RB}$ e SV.

Figura 1 - Fluxograma de atividades desenvolvidas

\begin{tabular}{|c|c|c|c|}
\hline $\begin{array}{l}\text { Apresentação } \\
\text { progressiva } \\
\text { dos textos } \\
\text { relativos à } \\
\text { disciplina }\end{array}$ & $\begin{array}{l}\text { Orientação } \\
\text { para leitura } \\
\text { e resumo } \\
\text { dos textos }\end{array}$ & $\begin{array}{l}\text { Discussão } \\
\text { colaborativa em } \\
\text { torno dos textos } \\
\text { na sala de aula }\end{array}$ & $\begin{array}{l}\text { Apresentação } \\
\text { das idéias } \\
\text { principais e } \\
\text { palavras-chave } \\
\text { pelos alunos/as }\end{array}$ \\
\hline
\end{tabular}
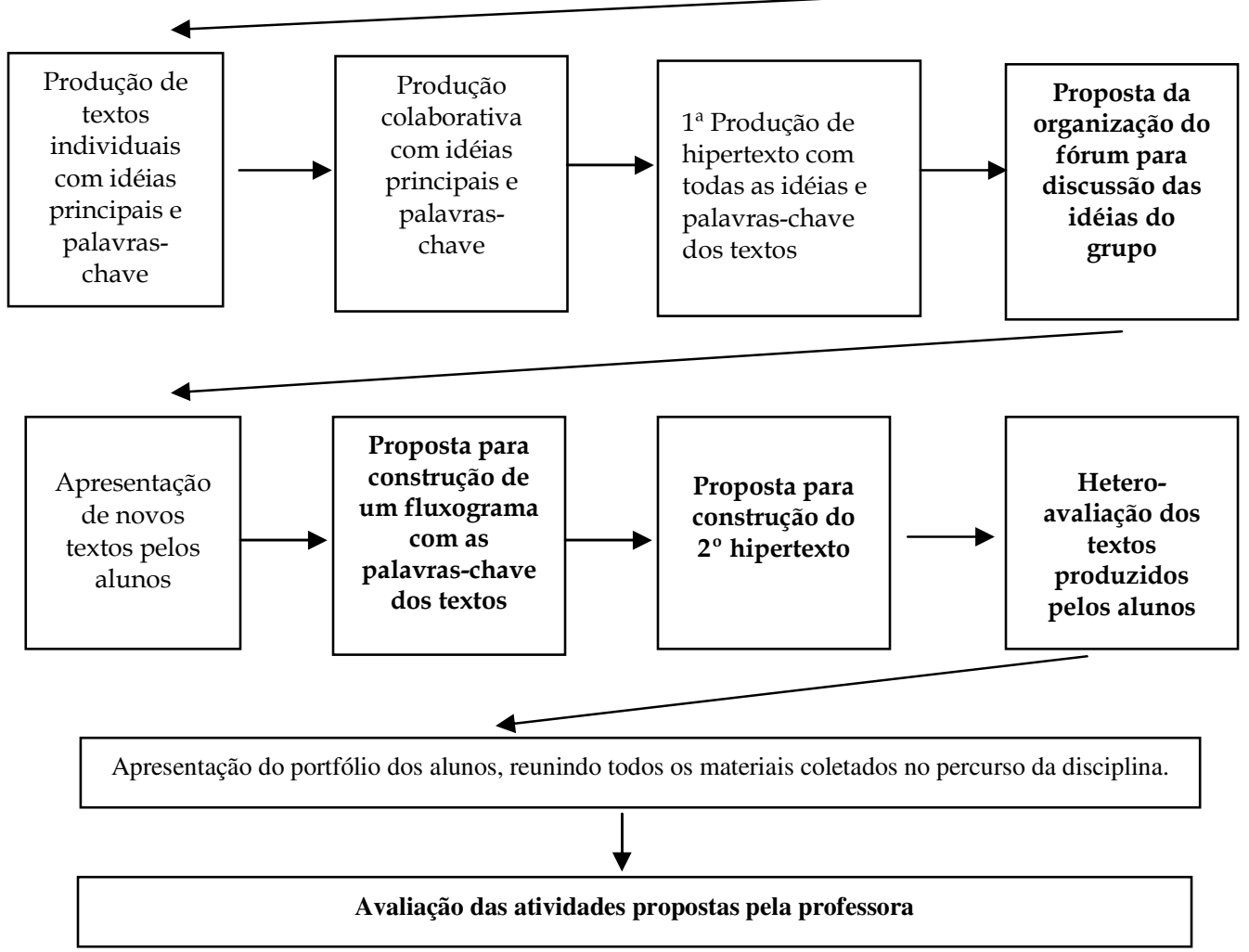
No fluxograma estão indicadas as atividades desenvolvidas no percurso da disciplina; o que está em negrito são as atividades consideradas mais significativas para o presente artigo.

O fluxograma mostra o caminho proposto para a disciplina, no sentido de articular todos os textos apresentados pela professora e pelos alunos, de forma a valorizar a rede de saberes que pode se constituir nas relações entre os links propiciados pela alternativa pedagógica sugerida na disciplina. É a busca do enfoque intradisciplinar e interdisciplinar, como integração das idéias no contexto da disciplina e da interface com outras disciplinas de temáticas conexas. É a emergência do pensamento em rede, compreendendo-se a rede como passagem para o paradigma cooperativo do conhecimento (Assmann, 2005). As redes funcionam como estruturas cognitivas interativas pelo fato de terem características hipertextuais e pela interferência possivel do conhecimento que outras pessoas construíram ou estão construindo (Assmann, 2005, p. 22).

Constitui-se como uma nova forma de aprender, ensinar e avaliar; entram em cena as redes digitais como propiciadoras de cooperação presencial e/ou online, considerando-se no caso do ensino presencial, num sentido lato sensu - uma sala de aula "inforica" (SILVA, 2002), isto é, espaço em que se apliquem diversos recursos midiáticos propostos aos alunos participantes.

\section{ANALISANDO E AVALIANDO A PROPOSTA}

A análise e a avaliação da alternativa pedagógica apresentada destacou as seguintes atividades desenvolvidas no percurso da disciplina, conforme sinalizado anteriormente: a experiência do fórum de discussão; a elaboração do fluxograma; as produções textuais dos alunos; e a avaliação das atividades desenvolvidas.

\subsection{A experiência do fórum de discussão}

Desde o início do curso foi constituído um grupo denominado Avaliação-Mediação, e sua formação deveu-se, em especial, à participação de BR. De início, a entrada no grupo propiciava a troca de materiais relacionados aos conteúdos estudados, mas nem todos os alunos conseguiram se conectar imediatamente, o que só ocorreu no início de outubro. Na primeira quinzena desse mês, a professora propôs a criação de um fórum de discussão. Preliminarmente, os participantes sugeriram a análise de textos da Internet, entre os quais o enviado no dia 5 de outubro 
por LD, sobre "Avaliação e suas dificuldades", e, num segundo momento, no dia 12 de outubro, dois textos indicados pela professora: Guttierrez e Prieto, (1994) e Gomez (2004). Apesar de ter começado no início de outubro, o fórum de discussão teve seu ponto alto na segunda quinzena. Apenas um aluno não participou; quatro alunos participaram apenas uma vez; outros quatro entraram duas vezes; um entrou três vezes; e outro participou quatro vezes; os mais assíduos foram três participantes, dos quais um entrou sete vezes, e dois participaram oito vezes.

Esta atividade teve uma repercussão favorável, sendo dinamizada, em especial, por LM e BR, que periodicamente entravam no fórum, enfocando as temáticas e respondendo as intervenções dos colegas.

O fórum foi iniciado por BR, que levantou a questão da grafia da expressão "educação a distância" que aparecia no texto de Gutierrrez e Prieto (1994) com crase. Após algumas consultas à Wickpédia e troca de idéias entre os participantes houve o consenso de que a expressão não tinha crase, embora ficasse evidenciado que na literatura eram usadas as duas formas (com e sem crase); outras questões ligadas à ortografia foram colocadas, como o termo online, que também aparecia na forma on-line; e o estrangeirismo $c d$-rom, lido como "ce-dê-rum", que segundo LD seria uma corruptela fonética. Essas breves colocações dos participantes podem ser interpretadas como preliminares e/ou preparatórias e são chamadas por Pichon-Rivière (1988, p.20) de "pré-tarefa" (antes da tarefa propriamente dita), sinalizando para o fato de que é indispensável um tempo preparatório, importante para serem atingidos os objetivos apontados inicialmente.

No dia 14 de outubro, BR estimulou a intervenção do grupo ao colocar aspectos do texto de Gutierrez e Prieto (1994) que foram importantes para a discussão. $\mathrm{O}$ primeiro ligado à citação dos autores - $O$ ideal de um sistema de auto-aprendizagem é a auto-avaliação - (p. 127) e o segundo relacionado à figura do assessor pedagógico como um facilitador (idem, p. 145).

Foi após essa entrada de BR, e possivelmente em razão do feriado de 15 de outubro - Dia do Mestre - que as participações se tornaram mais freqüentes. Nesse dia, às 11 horas, destacou-se a entrada de LM, citando Gomez (2004, p.178), que afirma as interfaces na mediação facilitam uma comunicação pautada na ética, o que leva à reflexão sobre a verificação de aprendizagem e à questão da honestidade e da ética pessoal; esta intervenção decorreu da consulta de alguns colegas sobre o fato de a avaliação no ensino a distância ser presencial, e que levou LM a citar o art. $7^{\circ}$ do Decreto n. 2494, sobre a regulamentação do artigo 80 da LDB (Lei n. 
9394/1996), que assiná-la: a avaliação do rendimento para promoção, certificação ou diplomação realizar-se-á por meio de exames presenciais.

Nesse dia, LM e BR, em especial, entraram várias vezes, até o momento em que LM se pronunciou sobre a "netiqueta":

Desculpem a quantidade de mensagens postadas por mim hoje. É que andei inspirado, mas não quero transgredir as regras de "netiqueta: não monopolizar as participações no fórum" (Gomez, 2004, p. 177), mas lá vai minha última (espero) mensagem de hoje: acho que pode ser inadequado pensar numa mediação antecipatória extremista. Se fizermos um recorte em Gutierrez e Prieto (1994, $p$. 129) "quando tudo se concentra no transpasse de informação na resposta esperada, temos um sistema baseado em controles e provas de retenção". Tudo é extremo, mas nada também seria (...) a retenção da informação é importante (...) mas transitar entre os extremos e dosar entre as situações não seria o caminho?

A intervenção de LM estava relacionada com o fato de que suas intervenções eram sistematicamente respondidas por BR, o que, de certa forma, monopolizava o espaço de discussão criado para todos os participantes.

Ao final do dia 15 de outubro, AV levantou questões tratadas por LM quanto à ética:

A esfera da ética citada por LM foi um dos pontos que me chamou a atenção. Pois é bem verdade que a lei obriga a presença dos alunos o que, de alguma forma, acaba com o conceito de EAD; quanto ao assessor pedagógico, se na prática funcionasse, seria um profissional de alto valor para as instituições de ensino. Eu acredito no potencial da EAD; acho que a mesma ainda não mostrou tudo que pode fazer, devido a inúmeras variáveis

Após a intervenção de $\mathrm{AV}, \mathrm{PB}$ entrou no fórum e se pronunciou a respeito da presença do aluno nas provas, nos cursos de EAD.

Para podermos analisar com isenção esse assunto precisamos eliminar as concepções que estão presentes em nossa formação, que é de que as avaliações devem ser pontuais e somativas (...) o problema passa a ser de custos $-\$ \$ \$$ - pois poucos poderão ser acompanhados pelo professor se adotado como critério de avaliação a abordagem processual (...) o custo professor/aluno será bem maior. Quanto ao assessor pedagógico tenho visto essa atribuição ser exercida pelo tutor.

\section{A seguir, AN fez uma intervenção:}

Os cuidados com a avaliação da EAD passam pela co-responsabilidade $e$ maturidade dos participantes e a forma como os mesmos encaram a sua aprendizagem. Existe uma falta de preparo dos educadores tradicionais e da EAD em avaliar seus pupilos. A preparação não passa do básico feijão com arroz, a 
prova; de acordo com Gutierrez e Prieto (1994, p. 145) "a EAD acabou por rebaixar a tarefa do mestre".

Na seqüência, NK concordou com o grupo e acrescentou:

A avaliação é realizada para medir o nível de aprendizagem e outorgar-lhe uma certificação, mas sem dúvida é um instrumento para melhorar o processo de ensinar e aprender, ou deveria ser, mas para tal se faz necessário uma mudança consistente em toda essa ação (...) seria possível uma avaliação democrática ou deveríamos permanecer no nível da avaliação autocrática e/ou burocrática?

A questão proposta por NK teve repercussão nos encontros presenciais, em razão da complexidade do processo de avaliar; é objeto de discussão tanto nos cursos presenciais, quanto nos cursos a distância.

No decorrer do dia 15 de outubro, LM propôs a realização de um chat, que não logrou o êxito esperado, por ser em um horário em que muitos dos participantes estavam trabalhando, o que impedia a sua participação. Ao final desse dia, AV levantou questões tratadas por LM sobre ética, pontuando a obrigatoriedade da presença dos alunos nos exames, o que, segundo AV, acaba por prejudicar a idéia de Educação a Distância.

PB demonstrou estar atento aos problemas que permeiam os processos da EAD, com seus argumentos e colocações, apoiado por NK que, em determinado momento, afirmou: a avaliação se tornou um processo mecânico, muito mais que um processo educativo.

A contribuição de MC foi interessante ao falar da utilização da videoconferência nos cursos - tema discutido em um dos textos propostos pela professora. Disse que, à parte dos problemas existentes com relação à avaliação online, a videoconferência contribuía significativamente, pois a imagem e o áudio simultâneos permitiam conhecer as diferentes opiniões dos interlocutores, além de reforçar tecnicamente a atitude dialógica. Essa modalidade conjuga os recursos tecnológicos e a possibilidade do próprio aluno poder estar diante de seu momento de avaliação, configurando a auto-avaliação.

CF foi um dos participantes que demorou a participar do fórum, pois entrou pela primeira vez no dia 23 de outubro. Comentou as intervenções de LD, AV, NA, BR, entre outras, mencionando uma citação do texto de Gutierrez e Prieto (1994), que alertava sobre o fato de que conforme as metodologias empregadas pelos professores, pode-se dizer quais serão os critérios de avaliação utilizados. Este alerta dos autores sinaliza para a relação entre as diferentes formas de avaliar e a necessidade 
de coerência nas situações de aprendizagem propostas, além de lembrar o compromisso de cada professor na definição dos critérios de avaliação.

No dia 21 de outubro, PB entrou e trouxe notícias sobre o artigo publicado em jornal "Barbárie vai à escola", que levantava questões a respeito dos processos de auto-avaliação.

LD ainda respondeu a MC, falando das barreiras a serem vencidas no caso da videoconferência sobre a velocidade, e citou o mestrado fora de sede da UFSC, que aplicava a referida tecnologia. PB se pronunciou e falou do curso do qual foi coordenador, que também utilizava a videoconferência, concordando, em parte, com relação à velocidade, mas argumentando que, a partir de sua experiência, representava uma estratégia interessante no aspecto interação-mediação online.

A opinião de LD sobre auto-avaliação foi instigante, ao questionar sua validade, não sua importância, quando ainda não há um amadurecimento prévio para alcançar um estado de prontidão, a fim de que a avaliação seja democrática, fidedigna, justa e contextualizada.

A atividade do fórum, descrita brevemente neste tópico, foi significativa para a disciplina em discussão, pois contribuiu para a questão da mediação pedagógica, a partir do compartilhamento de idéias entre os participantes sobre conteúdos como: critérios de avaliação, auto-avaliação, ética, legislação sobre o processo de avaliar, custos da EAD, metodologias de avaliação e videoconferência, entre outros.

\subsection{A elaboração do fluxograma}

Além da realização do fórum, foi proposta, pela professora, a elaboração de um fluxograma, que reunisse as palavras-chave dos textos estudados, relacionados aos conteúdos da disciplina, com o propósito de que fossem articulados os tópicos fundamentais dos eixos temáticos em foco. Embora fosse uma atividade aparentemente simples, para alguns alunos constituiu-se um desafio, tendo em vista que era fundamental a leitura de todos os textos para levantamento das palavras-chave.

Os fluxogramas tiveram formatos bem diferenciados; entretanto predominavam os temas tratados na disciplina, dos quais podemos destacar: a avaliação como tema polêmico; a articulação dos saberes; o currículo em rede; as diferentes modalidades de avaliação; a difusão de informações para muitos receptores; a ação reflexiva; a interação; a construção do conhecimento, e outros também discutidos pela professora e trazidos pelos alunos. Um dos alunos (LM) utilizou um programa para a elaboração de mapas conceituais, que, de modo bem interessante, oportunizou a discussão dos temas abordados. 
Essa atividade foi considerada coerente com os objetivos da disciplina, possibilitando favoravelmente as trocas e mediações entre alunos, e, em especial, entre alunos e professora, pois resultou em discussões férteis, no âmbito da avaliação e da mediação tecnológica.

\subsection{Temas emergentes das produções finais dos alunos: a produção hipertextual}

Este tópico apresenta uma breve análise e avaliação da proposta em tela, tomando aspectos significativos emergentes das produções dos alunos em dois momentos diferentes do curso. O primeiro ocorreu após oito aulas presenciais, e o segundo ao final do curso, que teve um total de 15 aulas. Após a leitura atenta das produções textuais dos alunos, nesses dois momentos, os seguintes temas foram destacados: a) relações entre aprendizagem e avaliação; b) o próprio processo de avaliação; c) a mediação tecnológica; d) a hipertextualidade; e e) os procedimentos online.

$\mathrm{O}$ primeiro tema relações entre aprendizagem e avaliação abordou um dos assuntos tratados durante a disciplina "Avaliação educacional e mediação tecnológica", pois essas relações são relevantes para o êxito do processo de aprendizagem. As seguintes falas ilustram esse tema:

NK - Os processos de ensino-aprendizagem e principalmente a avaliação constituem articulações indissociáveis. Temos ciência de que a produção do conhecimento passou por vários processos e etapas: o empirista, racionalista, construtivista, e dai a complexidade no processo. Os projetos educativos, que ainda insistirem em dicotomizar a relação sujeito-objeto, farão com que o sujeito não adquira a autonomia do conhecimento.

CF - Dessa forma, a mudança está no papel do professor e da avaliação que devem ser repensados, na medida em que cada vez mais as TIC demarcam sua presença na Educação, oferecendo desafios, dificuldades e oportunidades de desenvolvimento para a construção do conhecimento. O sentido da avaliação, portanto, não se desvincula do processo de aprendizagem.

$\mathrm{Na}$ perspectiva apresentada, as produções textuais dos alunos apóiam-se em Gutierrez e Prieto (1994, p. 131), que afirmam “o tratamento pedagógico tem como função essencial facilitar a obtenção de procedimentos adequados aos diferentes momentos de auto-aprendizagem: apropriação de informação, recriação, semântica, aplicabilidade, relação texto-contexto, invenção etc." Isso mostra, especialmente, a importância dos procedimentos do professor para alcançar seus objetivos, orientando os alunos para a construção do conhecimento e, assim, obter resultados favoráveis na avaliação. 
O segundo tema que surgiu na produção textual dos alunos foi o próprio processo de avaliação. A seguir, transcrevemos trechos relativos a esse tema: MC faz referência ao ensino online e AV ao processo de autoavaliação.

MC - O ciberespaço é o conjunto de interfaces que abrem um enorme potencial de aprendizado aos alunos via EAD, mas também pressupõe alguns cuidados, principalmente no que se refere às avaliações. Apesar de serem muitas as técnicas de avaliação o ensino online ainda utiliza a forma presencial como instrumento final da avaliação do aluno.

AV - Em um sistema de aprendizagem, a auto-avaliação é condição vital para que o juízo de valor dado pelo referente ao referido tenha sentido e feche com chave de ouro o processo.

Em relação à proposta de EAD, Gutierrez e Prieto (1994, p. 130) esclarecem nossa proposta de EAD culmina numa avaliação que pode integrar processos e produtos. Quanto maior for a riqueza do primeiro, melhores os produtos; quanto melhores forem estes maior aproveitamento haverá nos processos. Ratificam-se, nesse sentido, as possibilidades de procedimentos de avaliação online, tendo em vista as restrições para aplicar todo o potencial da EAD, em razão das limitações encontradas nos cursos. A colocação de AV tem respaldo em Gutierrez e Prieto (1994, p. 128) que falam da necessidade de a instituição aceitar que está trabalhando com pessoas maduras para serem capazes de se avaliar a si mesmas.

Quanto ao tema mediação tecnológica, foram inúmeras as falas que se relacionavam a esse assunto, das quais destacamos:

SV - A avaliação educacional, como um somatório de todas as avaliações, se vêe diante da avaliação online. Enquanto a avaliação tradicional conta apenas com os instrumentos já conhecidos pela maioria dos professores, a avaliação online possui uma pluralidade de instrumentos, o que facilita ao professor a tarefa tão difícil que é a de avaliar. Interessante é também a avaliação tradicional que, aos poucos, começa a fazer a mediação tecnológica como mais um instrumento de avaliação, pois avaliar só tem sentido se for para aprimorar o processo de aprendizagem.

LM - Foi abordada a possibilidade da mediação tecnológica online e a distância. O texto de Filatro (2004) não só justifica a importância da mediação pela tecnologia, principalmente a distância, como forma de integrar as exigências individuais e sociais às novas demandas do mundo do trabalho, de comunicação e da informação, mas também questiona e discute os desafios, benefícios e dificuldades com a introdução das TIC. 
Além de Filatro (2004, p. 47), Gutierrez e Prieto (1994) também consideram que a tarefa da mediação estará a cargo da equipe em que o autor teria que estar integrado como mais um para avaliar, e talvez um dos mais importantes membros. Assim, a sustentação teórica abrangeria três pontos: (a) a auto-aprendizagem; (b) o interlocutor presente e (c) o jogo pedagógico (p. 78).

Gutierrez e Prietto (1994, p. 79) esclarecem que num processo alternativo trata-se de oferecer elementos para aprender a realizar a autoaprendizagem. Assim, a responsabilidade não recai apenas no estudante, mas também em todos os envolvidos, e, de modo especial, nas características dos materiais. Esse ponto é tão importante quanto o da presença do interlocutor, e culmina com o do jogo pedagógico, que exige a prática de procedimentos alternativos para a EAD.

$O$ terceiro tema enfocou a hipertextualidade que se constitui no eixo central dos objetivos da disciplina, enquanto propiciadora da produção hipertextual dos alunos. Nessa atividade final, houve oportunidade para emergirem idéias significativas sobre esse aspecto:

BR - Assim na web, as possibilidades de criação são maximizadas pelo meio digital, que permite que os cursos de EAD gerem espaços de navegação hipertextual. Dai a necessidade de ferramental que auxilie o usuário a não se perder, além de conteúdos claros e convidativos.

$\mathrm{MB}-A$ EAD traz recursos do mundo virtual que facilitam o relacionamento entre professor e aluno, tornando a troca de saberes mais significativa e interessante. $O$ conhecimento não está atrelado somente às informações. O aluno pode construir novos percursos de leituras, não se submetendo mais à transmissão ou emissão por parte do professor. Diante das possibilidades do hipertexto informático ele pode deixar de ser um consumidor de informação e construir sua autoria na exploração.

As transcrições dos alunos indicam as possibilidades de comunicação na web, entre as quais são lembradas por Souza (2003, p.96): e-mail; listas de discussão, fóruns e new-groups; ambiente de conversação online ou chats; ambientes de imersão virtual; ambiente de aprendizagem na web; portais da web; webrings; serviços de compartilhamento de arquivo. Para a efetivação da aprendizagem e construção de espaços de autoria, a navegação na web, as trocas compartilhadas, presencialmente e online, foram consideradas significativas pelos participantes durante o percurso da disciplina.

\subsection{A avaliação das atividades desenvolvidas}

Ao final do período, foi realizada a avaliação das atividades propostas na disciplina, em quatro tópicos: a) o fórum de discussão; b) a elaboração do fluxograma; c) a hetero-avaliação; d) a auto-avaliação. Em 
cada questão os participantes poderiam atribuir os valores: MB (muito bom); B (bom); R (regular); F (fraco) e MF (muito fraco). Vale esclarecer que apenas um dos alunos não participou.

À primeira questão, relativa as atividades do fórum, oito respondentes atribuíram o valor $\mathrm{MB}$, três optaram pelo $\mathrm{B}$, uma das alunas atribuiu o valor $\mathrm{R}$, e outra o valor $\mathrm{F}$. Algumas respostas abertas sobre este item são transcritas a seguir:

PB - Bom, podia ser melhor, com a participação maior dos alunos.

BR - É um recurso extremamente válido, mas foi subutilizado. O chat também é outra ferramenta muito boa, que não foi utilizada plenamente.

LM - Possibilita a exposição de idéias de forma mais livre, sem a restrição do tempo de atividade em classe. Faltou um pouco de dinamismo, e houve alguma dispersão.

À segunda pergunta, que abordou a elaboração do fluxograma, oito participantes atribuíram $\mathrm{MB}$, três assinalaram $\mathrm{B}$, e dois alunos não responderam. Abaixo, destacamos algumas respostas abertas sobre esse item:

CF - Organiza e ajuda a sintetizar as idéias, permitindo reunir ou consolidar os assuntos discutidos.

AV - O fluxograma é uma ótima maneira de organizar as idéias, relembrar os tópicos discutidos e avaliar melhor o seu aprendizado.

NK - Acrescentou muito à minha formação profissional, para a elaboração e organização das idéias e contextualização dos temas abordados.

No que diz respeito à atividade sugerida pela professora de heteroavaliação do fluxograma, cinco alunos consideraram-na $\mathrm{MB}$ e seis a analisaram como B. A seguir, algumas respostas dos participantes

CF - Permite familiarizar-se com as idéias do outro, conhecendo sua lógica e visões diferentes.

MC - Abre possibilidades de rever (meu caso) a sistematização feita, sob o olhar de outra pessoa. Abre a discussão e amplia a visão do tema.

GC - Achei ótima a idéia de outra pessoa avaliar o meu fluxograma, pois dá a noção exata se o que escrevemos as outras pessoas entendem. 
$\mathrm{O}$ último item enfocava a auto-avaliação, que foi considerada $\mathrm{MB}$ por três participantes, oito atribuíram $\mathrm{B}$ à sua participação, uma considerou-a F, e um não respondeu. A seguir, apresentamos as respostas abertas a esse questionamento.

LD - É a minha primeira disciplina no Mestrado, melhorei muito em relação ao meu estágio inicial.

MI - Infelizmente, neste semestre acabei tendo uma sobrecarga de exigências profissionais que me impediram de participar de forma efetiva nas atividades desenvolvidas.

SV - Apesar das dificuldades com a tecnologia, o estudo foi importante para mim. Li bastante e consegui entender e manipular melhor o computador e saber mais sobre avaliação que e um assunto vasto e sempre presente no contexto educacional.

Esta etapa do processo foi muito importante, visto que reuniu três momentos do processo de avaliar - avaliação da disciplina, heteroavaliação e auto-avaliação -, na perspectiva de analisar a disciplina, rever as estratégias utilizadas, verificando os pontos frágeis e os pontos fortes para a atuação do professor em próximas disciplinas. Ficou evidente, pelas sugestões dos alunos durante os encontros presenciais, a necessidade da atividade do fórum de discussão ser iniciada com questões norteadoras para os alunos, com a finalidade de ampliar a participação do grupo.

Pode-se constatar, em relação ao fluxograma, que os resultados foram favoráveis para esse grupo de alunos, apontando, num primeiro momento, para a possibilidade de organização de idéias vinculadas aos conteúdos da disciplina, e, posteriormente, com a hetero-avaliação, rever como suas idéias são apreciadas pelo outro, alem de analisar como o outro entende o que escrevemos. A auto-avaliação constituiu um ponto importante nesse processo, pois foi esclarecido, no decorrer da disciplina, que é o próprio sujeito da avaliação quem melhor pode avaliar.

\section{BREVES CONSIDERAÇÕES FINAIS}

Ao final, os alunos apresentaram o portfólio, em $c d$-rom, no qual estavam registradas todas as atividades desenvolvidas durante a disciplina. No percurso do semestre, foram evidenciados alguns aspectos significativos para a experiência desenvolvida: a) o primeiro referiu-se às possibilidades de cooperação obtida por meio da criação do grupo Avaliação-Mediação, que favoreceu o diálogo, o compartilhamento de idéias, e, em decorrência, possivelmente, a aprendizagem dos conteúdos 
pelos alunos; b) o segundo relacionou-se à constatação das perspectivas de articulação entre os conceitos analisados por meio da elaboração dos resumos dos textos e levantamento das palavras-chave, e, em conseqüência, a qualidade das produções hipertextuais apresentadas; c) o êxito do fórum, realizado de 15 a 30 de outubro, para a discussão dos temas especialmente vinculados à mediação pedagógica (Guttierrez, Prieto, 1994) e sobre a avaliação em EAD (Gomez, 2004); e d) a apresentação do portfólio, confirmando as expectativas em relação à adequação dessa estratégia para a avaliação presencial, como favorecedora de uma visão ampla das atividades realizadas.

Por fim, pode-se afirmar que a alternativa de avaliação, realizada nessa disciplina, apontou aspectos favoráveis, entre os quais podem ser destacados: a elaboração do fluxograma e a própria organização do portfólio, que evidenciaram as possibilidades de articulação entre os temas analisados pelos participantes. Como aspecto desfavorável, pode ser assinalada a forma como foi proposto o fórum, que poderia ter sido norteado por questões sugeridas pelo professor, com certa antecedência, objetivando a reflexão sobre aspectos relevantes do processo de avaliação. Esses pontos foram indicadores para a revisão dos procedimentos a serem aplicados em disciplinas ministradas nos próximos semestres, relativas à aplicação da modalidade de avaliar experenciada, apontando o compromisso contínuo do professor no aprimoramento das atividades de aprender, ensinar e avaliar.

\section{REFERÊNCIAS BIBLIOGRÁFICAS}

ASSMANN, H. Redes digitais e metamorfose do aprender. Petrópolis: Vozes, 2005.

COSCARELLI, C. V. Entre textos e hipertextos In: (org.) Novas tecnologias, novos textos e novas formas de pensar. Belo Horizonte: Autêntica, 2003. p.65-84.

COSCARELLI, C. V.; RIBEIRO, A. E. (orgs.) Letramento digital: aspectos sociais e possibilidades pedagógicas. Belo Horizonte: Ceale; Autêntica, 2005.

FILATRO, A. Design instrucional contextualizado: educação e tecnologia. São Paulo: Editora Senac, 2004. 
GOULART, C. Letramento e novas tecnologias. In: COSCARELLI, C. V.; RIBEIRO, A. E. (orgs.) Letramento digital: aspectos sociais e possibilidades pedagógicas. Belo Horizonte Ceale: Autêntica, 2005. p. 41-58.

GOMEZ, M. Educação em rede: uma visão emancipatória. São Paulo: Cortez; Instituto Paulo Freire, 2004.

GUTIERREZ, F.; PRIETO, D. A mediação pedagógica: educação a distância alternativa. Campinas, SP: Papirus, 1994

LEVY, P. Cibercultura. São Paulo: Ed. 34, 1999.

A inteligência coletiva. São Paulo: Ed. 34, 1998

PICHON-RIVIÈRE, E. O processo grupal. São Paulo: Martins Fontes, 1988.

SILVA, M. Sala de aula interativa. Rio de Janeiro: Quartet, 2002.

SOARES, M. Letramento: um tema em três gêneros. Belo Horizonte: Autêntica, 1998.

jul./ago. 2003.

A Reinvenção da alfabetização. Presença Pedagógica, v. 9, n.52,

Novas práticas de leitura e escrita: letramento na cibercultura. Educação E Sociedade, v. 23, n.81, p. 143-162, dez. 2002.

SOUSA, R. R. O Caso das listas de discussão. In: COSCARELLI, C. V. (org.) Novas tecnologias, novos textos e novas formas de pensar. Belo Horizonte: Autêntica, 2003. p.95-109.

Recebido em: janeiro 2007

Aprovado para publicação em: maio 2007 
